\title{
Platelet HIF-2 $\alpha$ promotes thrombogenicity through PAI-1 synthesis and extracellular vesicle release
}

Haematologica 2019

Volume 104(12):2482-2492

\section{Correspondence: \\ DEBABRATA DASH \\ ddash.biochem@gmail.com \\ Received: January 24, 2019. \\ Accepted: April 17, 2019. \\ Pre-published: April 19, 2019.}

doi:10.3324/haematol.2019.217463

Check the online version for the most updated information on this article, online supplements, and information on authorship \& disclosures: www.haematologica.org/content/104/12/2482

(C)2019 Ferrata Storti Foundation

Material published in Haematologica is covered by copyright. All rights are reserved to the Ferrata Storti Foundation. Use of published material is allowed under the following terms and conditions:

https://creativecommons.org/licenses/by-nc/4.0/legalcode. Copies of published material are allowed for personal or internal use. Sharing published material for non-commercial purposes is subject to the following conditions: https://creativecommons.org/licenses/by-nc/4.0/legalcode, sect. 3. Reproducing and sharing published material for commercial purposes is not allowed without permission in writing from the publisher.

\author{
Susheel N. Chaurasia, ${ }^{1}$ Geeta Kushwaha, ${ }^{1}$ Paresh P. Kulkarni, ${ }^{1}$ \\ Ram L. Mallick, ${ }^{2}$ Nazmy A. Latheef, ${ }^{3}$ Jai K. Mishra ${ }^{3}$ and Debabrata Dash ${ }^{1}$ \\ ${ }^{1}$ Department of Biochemistry, Institute of Medical Sciences, Banaras Hindu University, \\ Varanasi, India; 'Department of Biochemistry, Birat Medical College \& Teaching Hospital, \\ Biratnagar, Nepal and ${ }^{3}$ Department of Tuberculosis \& Respiratory Diseases, Institute of \\ Medical Sciences, Banaras Hindu University, Varanasi, India
}

\section{ABSTRACT}

O xygen-compromised environments, such as high altitude, are associated with platelet hyperactivity. Platelets confined within the relatively impervious core of an aggregate/thrombus have restricted access to oxygen, yet they continue to perform energy-intensive procoagulant activities that sustain the thrombus. Studying platelet signaling under hypoxia is, therefore, critical to our understanding of the mechanistic basis of thrombus stability. We report here that hypoxia-inducible factor (HIF)- $2 \alpha$ is translated from pre-existing mRNA and stabilized against proteolytic degradation in enucleate platelets exposed to hypoxia. Hypoxic stress, too, stimulates platelets to synthesize plasminogen-activator inhibitor-1 (PAI-1) and shed extracellular vesicles, both of which potentially contribute to the prothrombotic phenotype associated with hypoxia. Stabilization of HIF- $\alpha$ by administering hypoxia-mimetics to mice accelerates thrombus formation in mesenteric arterioles. In agreement, platelets from patients with chronic obstructive pulmonary disease and high altitude residents exhibiting thrombogenic attributes have abundant expression of HIF- $2 \alpha$ and PAI1. Thus, targeting platelet hypoxia signaling could be an effective antithrombotic strategy.

\section{Introduction}

The essence of platelet function is response to stimuli. Once stimulated, platelets rapidly adhere to each other to form macroscopic aggregates. A thrombus is a meshwork of polymerized fibrin holding aggregated platelets and is essential for hemostasis. Intriguingly, platelets continue to perform energy-intensive tasks such as protein synthesis, retraction of the fibrin clot and shedding of extracellular vesicles (EV) while trapped within the tightly packed thrombus milieu, despite the fact that these cells remain significantly cut off from supplies of oxygen and nutrients. Understandably, access to oxygen drops progressively from the periphery of a mass of platelet aggregate (or thrombus) to its inner core, which would expose the platelets to a differential hypoxic stress. Notably, phosphatidylserine-positive platelets are known to be localized at the core of a thrombus. ${ }^{1}$ Platelet response to hypoxia could influence the stability of platelet aggregates as well as sustenance of the thrombus. Thus, targeting hypoxia signaling could be an effective therapeutic strategy to destabilize pathological thrombi. As little is known about signaling dynamics in platelets exposed to hypoxic stress, in this study we explored the nature of hypoxia signaling and its regulation in human platelets.

Hypoxia-inducible factor (HIF) consists of an oxygen sensing $\alpha$ subunit and a constitutively expressed $\beta$ subunit and has a central role in oxygen homeostasis. ${ }^{2}$ The $\alpha$ subunit exists in three oxygen-sensitive isoforms (HIF-1 $\alpha,-2 \alpha$ and $-3 \alpha){ }^{3} \mathrm{HIF}-$ $1 \alpha$ is ubiquitously expressed while the presence of HIF- $2 \alpha$ and $-3 \alpha$ is cell-specific. ${ }^{4,5}$ The stability of HIF- $\alpha$ is determined by the hydroxylation status of specific proline residues catalyzed by prolyl hydroxylases (PHD1, 2 and 3), which are molecular oxygen-, 2-oxoglutarate-, and iron-dependent enzymes, ${ }^{2,6}$ Under normoxia, 
hydroxylated HIF- $\alpha$ subunits are ubiquitinated by the von Hippel-Lindau tumor suppressor (pVHL) E3 ligase complex and HIF is targeted for proteasomal degradation., ${ }^{2,4}$ Under hypoxia, oxygen-sensing prolyl hydroxylases fail to hydroxylate HIF- $\alpha$, leading to this latter's stabilization. HIF can also be stabilized by non-hypoxic stimuli, including thrombin, ${ }^{7}$ as well as by hypoxia-mimetics such as dimethyloxalylglycine (DMOG) and deferoxamine (DFO). ${ }^{8}$ Interestingly, there have also been recent reports of HIF degradation mediated through either autophagy ${ }^{9}$ or chaperone-mediated lysosomal autophagy. ${ }^{10}$

Oxygen-compromised environments such as a high altitude and sports are associated with a higher incidence of thrombosis. ${ }^{11}$ Patients with pathological conditions associated with hypoxia, such as chronic obstructive pulmonary disease (COPD) and sleep apnea, have also been reported to have hyperactive platelets in their circulation as well as an increased risk of thrombosis. ${ }^{12-15}$ A recent study has correlated platelet hyperactivity under hypoxic stress with enhanced activity of the cysteine protease calpain. ${ }^{16}$ Hypoxia has been shown to enhance synthesis of thrombogenic molecules such as tissue factor ${ }^{17}$ and plasminogenactivator inhibitor-1 (PAI-1) ${ }^{18}$ in murine lung cells. Little is known about the mechanistic basis of platelet responses to hypoxia and adaptation of these cells to an oxygencompromised environment prevalent within cell aggregates or fibrin-rich thrombi. Platelets are enucleate cells with restricted ability for de novo protein synthesis by translation. The repertoire of proteins known to be synthesized by platelets is limited but includes $\mathrm{Bcl}-3,{ }^{19}$ interleukin-1 $\beta,{ }^{20}$ PAI- $1,{ }^{21}$ and tissue factor among others. ${ }^{22}$ The present study adds HIF- $2 \alpha$ to this growing list of the platelet translatome. HIF-2 $\alpha$ translation is induced in platelets by hypoxia, hypoxia-mimetics and physiological agonists such as collagen, thrombin or ADP. Inhibitors of either protein synthesis or mitogen-activated protein kinase (MAPK) markedly depress HIF-2 $\alpha$ synthesis. Our results implicate both proteasome-mediated as well as lysosome-mediated pathways in the degradation of HIF$2 \alpha$ in platelets. Hypoxia and hypoxia-mimetics induce synthesis of PAI-1 in platelets and shedding of EV, both of which contribute to the evolution of a prothrombotic phenotype. Consistently with this, mice pretreated with hypoxia-mimetics, which would trigger platelet hypoxia signaling by stabilizing HIF- $\alpha$, exhibited accelerated arterial thrombosis. Circulating platelets from patients with COPD as well as a highland population were found to have significantly higher expression of HIF- $2 \alpha$ and PAI-1 compared to their control counterparts, which are findings coherent with the platelet hyperactivity reported in these subjects. ${ }^{11,12}$

\section{Methods}

\section{Ethical approval}

Animal experiments were approved by the Central Animal Ethical Committee of Banaras Hindu University. All efforts were made to minimize the number of animals used, and their suffering. Venous blood samples were collected from human participants at the University after obtaining written informed consent, strictly as per recommendations and as approved by the Institutional Ethical Committee of the Institute of Medical Sciences, Banaras Hindu University. The study was conducted according to standards set by the Declaration of Helsinki.

\section{Platelet preparation and materials}

Platelets were isolated from fresh venous human blood by differential centrifugation, as described elsewhere..$^{23}$ The sources of materials and additional methods are detailed in the Online Supplementary Data.

\section{Western analysis}

Platelet proteins were separated by sodium dodecylsulfate polyacrylamide gel electrophoresis (SDS-PAGE) and electrophoretically transferred onto polyvinylidene fluoride membranes. Following blocking, membranes were incubated with primary antibodies (anti-HIF-1 $\alpha$, 1:500; anti-HIF-2 $\alpha$, 1:500; anti-PAI-1, 1:100; antiactin, 1:5000) and horseradish peroxidase-conjugated secondary antibodies (goat anti-mouse, 1:1500, for HIF-1 $\alpha$ and PAI-1; goat anti-rabbit, 1:2000, for HIF-2 $\alpha$, and 1:40000, for actin). Antibody binding was detected using enhanced chemiluminescence.

\section{Total RNA extraction, reverse transcription and quantitative real-time polymerase chain reaction}

RNA was extracted from platelets and reverse transcribed to complementary DNA. The quantitative polymerase chain reaction (PCR) was initiated at $95^{\circ} \mathrm{C}$ for $3 \mathrm{~min}$, followed by 40 cycles of denaturation $\left(10 \mathrm{~s}\right.$ at $\left.95^{\circ} \mathrm{C}\right)$, annealing $\left(10 \mathrm{~s}\right.$, at $56^{\circ} \mathrm{C}$ for GAPDH, and at $59.2^{\circ} \mathrm{C}$ for both HIF- $1 \alpha$ and $-2 \alpha$ ) and extension at $72^{\circ} \mathrm{C}$.

\section{Hypoxic stimulation of isolated human platelets}

Isolated human platelets were exposed to hypoxia $\left(1 \% \mathrm{O}_{2}, 5 \%\right.$ $\mathrm{CO}_{2}$, and $94 \% \mathrm{~N}_{2}$ ) for the indicated time periods in an automatically controlled hypoxia chamber glove box (Plas-Labs) at room temperature. After completion of incubation, cells were lysed inside the hypoxia chamber to avoid their re-oxygenation.

\section{Isolation and analysis of platelet-derived extracellular vesicles}

Platelets were sedimented at $800 \times \mathrm{g}$ for $10 \mathrm{~min}$ followed by $1200 \times g$ for $2 \mathrm{~min}$ at $22^{\circ} \mathrm{C}$ to obtain platelet-derived extracellular vesicles (PEV) cleared of platelets. PEV in supernatant were analyzed by a Nanoparticle Tracking Analyzer.

\section{Intravital imaging of mesenteric arteriolar thrombi}

Ferric chloride-induced mesenteric arteriolar thrombi in mice were imaged as described previously, ${ }^{24}$ with minor modifications.

\section{Measurement of intracellular free calcium}

Intracellular free calcium was measured in Fura 2-acetoxymethyl ester (Fura-2 AM)-stained platelets as described in the Online Supplementary Data and calibrated according to the derivation of Grynkiewicz et al..$^{25}$

\section{Analysis of platelets from patients with chronic obstructive pulmonary disease and individuals living at high altitude}

Blood was collected from ten patients suffering from an acute exacerbation of COPD (arterial $\mathrm{PaO}_{2}<60 \mathrm{mmHg}$ ) admitted to Sir Sunderlal Hospital, Banaras Hindu University, and an equal number of age-matched healthy controls (arterial $\mathrm{PaO}_{2}>90 \mathrm{mmHg}$ ) (Online Supplementary Table S1). Exclusion criteria for both groups were domiciliary oxygen therapy, active smoking, hypertension, diabetes mellitus, malignancies and use of antiplatelet drugs. Arterial blood gas analysis was carried out using a Cobas B 121 Analyzer. Platelets were isolated from these samples and subjected to further studies.

Blood was also collected, with written informed consent, from ten healthy residents from Dhankuta, Nepal, which is $2200 \mathrm{~m}$ 
above sea level, and an equal number of age-matched, lowlander controls. Platelets were isolated from blood and subjected to western blot analysis.

\section{Results}

\section{Human platelets express HIF- $2 \alpha$}

HIF- $2 \alpha$ is known to be expressed in a cell-specific manner $^{26,27}$ unlike HIF-1 $\alpha$, which is ubiquitously expressed. Here, for the first time, we report that normoxic, unstimulated human platelets in the circulation express HIF-2 $\alpha$ and that the expression of this factor is increased considerably upon exposure of the platelets to hypoxic stress (Figure 1A). However, we did not detect HIF-1 $\alpha$ in platelets using specific antibodies in any of the above experimental conditions (data not shown).

As enucleate platelets with restricted protein synthesizing ability carry functional mRNA for a limited number of genes, we next examined the expression of HIF transcripts in these cells by quantitative PCR. The quantification cycle (Cq) of GAPDH (the endogenous control) was determined at $21 \pm 2$ while the Cq for HIF- $1 \alpha$ and $-2 \alpha$ were determined at $24 \pm 2$ and $25 \pm 2.5$, respectively, consistent with the presence of mRNA for both these isoforms in platelets. Non-specific amplification was ruled out by melt peak analysis (Online Supplementary Figure S1). Data from droplet digital PCR also supported the expression of mRNA for both HIF-1 $\alpha$ and $-2 \alpha$ in platelets (data not shown).

\section{Expression of HIF-2 $\alpha$ in human platelets is augmented upon exposure to either hypoxic stress or physiological agonists}

The oxygen-sensing $\alpha$ subunit of HIF is stabilized under oxygen-compromised states, ${ }^{2}$ as well as upon exposure of cells to non-hypoxic stimuli such as thrombin.? In order to examine hypoxic adaptation of platelets, we incubated the cells under low oxygen concentration $\left(1 \% \mathrm{O}_{2}, 5 \% \mathrm{CO}_{2}\right.$, and $94 \% \mathrm{~N}_{2}$ ) for the indicated periods. Expression of HIF$2 \alpha$ increased significantly and progressively with time under hypoxia (Figure 1A, C). Platelets stored under normoxia for similar durations also exhibited minor increases in HIF- $2 \alpha$ expression, although significantly less than those under hypoxia (data not shown). Interestingly, exposure to physiological agonists (thrombin, $1 \mathrm{U} / \mathrm{mL}$; ADP, 10 $\mu \mathrm{M}$; or collagen $10 \mu \mathrm{g} / \mathrm{mL}$ ) for $10 \mathrm{~min}$ evoked significantly higher expression of HIF- $2 \alpha$ in platelets in a normoxic environment, compared with unstimulated counterparts (Figure 1B, D). This observation underscored the presence of oxygen-independent HIF regulation, too, in platelets. As a thrombus is composed of stimulated platelets with restricted access to oxygen, these cells would have augmented HIF- $2 \alpha$ expression.

Regulation of HIF demands a consistent turnover and generation of polypeptides from mRNA transcripts. As enucleate platelets have remarkably limited capacity for protein synthesis due to a restricted pool of transcripts, we next studied HIF- $2 \alpha$ mRNA-protein translation by preincubating platelets with puromycin $(10 \mathrm{mM})$ before exposure to either hypoxia or thrombin. Puromycin decreased HIF-2 $\alpha$ expression in hypoxia-exposed $\left(1 \% \mathrm{O}_{2}\right.$, $5 \% \mathrm{CO}_{2}$, and $94 \% \mathrm{~N}_{2}, 30 \mathrm{~min}$ ) as well as thrombin-stimulated $(1 \mathrm{U} / \mathrm{mL}, 10 \mathrm{~min})$ platelets by $22.72 \%$ and $33.34 \%$, respectively (Figure 1E, F, H, I). p38 MAPK has been impli- cated in the upregulation of HIF-1 $\alpha$ in vascular smooth muscle cells. ${ }^{7}$ As this kinase is known to be expressed in human platelets and activated by thrombin, ${ }^{28}$ we studied its influence on HIF-2 $\alpha$ expression in platelets. Pre-treatment of platelets with SB202190, an inhibitor of p38 MAPK, led to a significant decrease in thrombin-induced HIF-2 $\alpha$ expression in a dose-dependent manner (inhibition by $16.43 \%$ and $28.77 \%$ with 20 and $40 \mu \mathrm{M}$ of SB202190, respectively) (Figure 1G, J).

\section{HIF-2 $\alpha$ turnover in human platelets}

HIF is known to be degraded by proteasomes aided by the activities of prolyl hydroxylases and the pVHL-E3 ligase complex. Lysosomes, too, have recently been implicated in HIF proteolysis by either macroautophagy or chaperone-mediated autophagy. ${ }^{10}$ The presence of a functionally active ubiquitin-proteasome system in human platelets has already been demonstrated. ${ }^{29}$ In order to ascertain proteasomal degradation of HIF- $2 \alpha$ in platelets, we treated normoxic cells with proteasome inhibitors, PSI $(50 \mu \mathrm{M})$ and MG132 $(50 \mu \mathrm{M})$, for $30 \mathrm{~min}$. Attenuation of proteasome peptidase activity was associated with a significant rise in HIF-2 $\alpha$ level in platelets (Figure 2A, D). Next, in order to determine the role of lysosomes in HIF-2 $\alpha$ proteolysis, we pre-incubated platelets with either bafilomycin A1 (250 nM) (which blocks the activity of vacuolarATPase proton pumps) or chloroquine $(50 \mu \mathrm{M})$ (which neutralizes the acidic environment within the lysosome compartment) for $30 \mathrm{~min}$. Platelets were then exposed to hypoxia $\left(1 \% \mathrm{O}_{2}, 5 \% \mathrm{CO}_{2}\right.$, and $\left.94 \% \mathrm{~N}_{2}\right)$ for $30 \mathrm{~min}$ or thrombin $(1 \mathrm{U} / \mathrm{mL})$ for $10 \mathrm{~min}$ at $37^{\circ} \mathrm{C}$. Remarkably, each of the inhibitors significantly increased the levels of HIF$2 \alpha$ in both hypoxic as well as thrombin-stimulated platelets (Figure 2B, C, E, F). Furthermore, we also determined the contribution of macroautophagy in HIF- $2 \alpha$ proteolysis. Cells were pretreated with 3-methyladenine (5 $\mathrm{mM}$ ) (an inhibitor of macroautophagy) for $30 \mathrm{~min}$ and then exposed to hypoxia for $30 \mathrm{~min}$. Inhibition of macroautophagy by 3-methyladenine led to significant increases in HIF-2 $\alpha$ levels in platelets as compared to levels in the vehicle-treated control (Figure 2B, E), thus implicating macroautophagy in the degradation of HIF- $2 \alpha$ under hypoxic conditions. Taken together, the results shown in Figure 2 suggest that HIF- $2 \alpha$ in platelets is degraded through both proteasomal and lysosomal proteolytic systems.

\section{Hypoxia and hypoxia-mimetics induce prothrombotic states through shedding of extracellular vesicles and synthesis of PAI-1 in human platelets}

Platelets are known to remain 'hyperactive' in oxygencompromised states ${ }^{11-13}$ potentially leading to thrombotic episodes. Thrombus stabilization is facilitated by PAI-1, a member of the serine protease-inhibitor superfamily. Platelets synthesize functionally active PAI-1 from preexisting mRNA. ${ }^{21}$ PAI-1 has been shown to be the target gene of HIF- $2 \alpha$ in renal carcinoma cells. ${ }^{30}$ As HIF- $\alpha$ expression is induced in platelets under hypoxia or upon exposure to hypoxia-mimetics such as DMOG (1 mM) and DFO $(1 \mathrm{mM})$ (which stabiize HIF-2 $\alpha$ by inhibition of prolyl hydroxylases), we next asked whether synthesis of PAI-1, too, is induced in platelets under these conditions. Exposure of human platelets to hypoxia (Figure 3A, D), DMOG and DFO (Figure $3 \mathrm{~B}, \mathrm{E}$ ) upregulated the expression of PAI- 1 by $50.06 \%, 41.35 \%$ and $51.87 \%$, respective- 

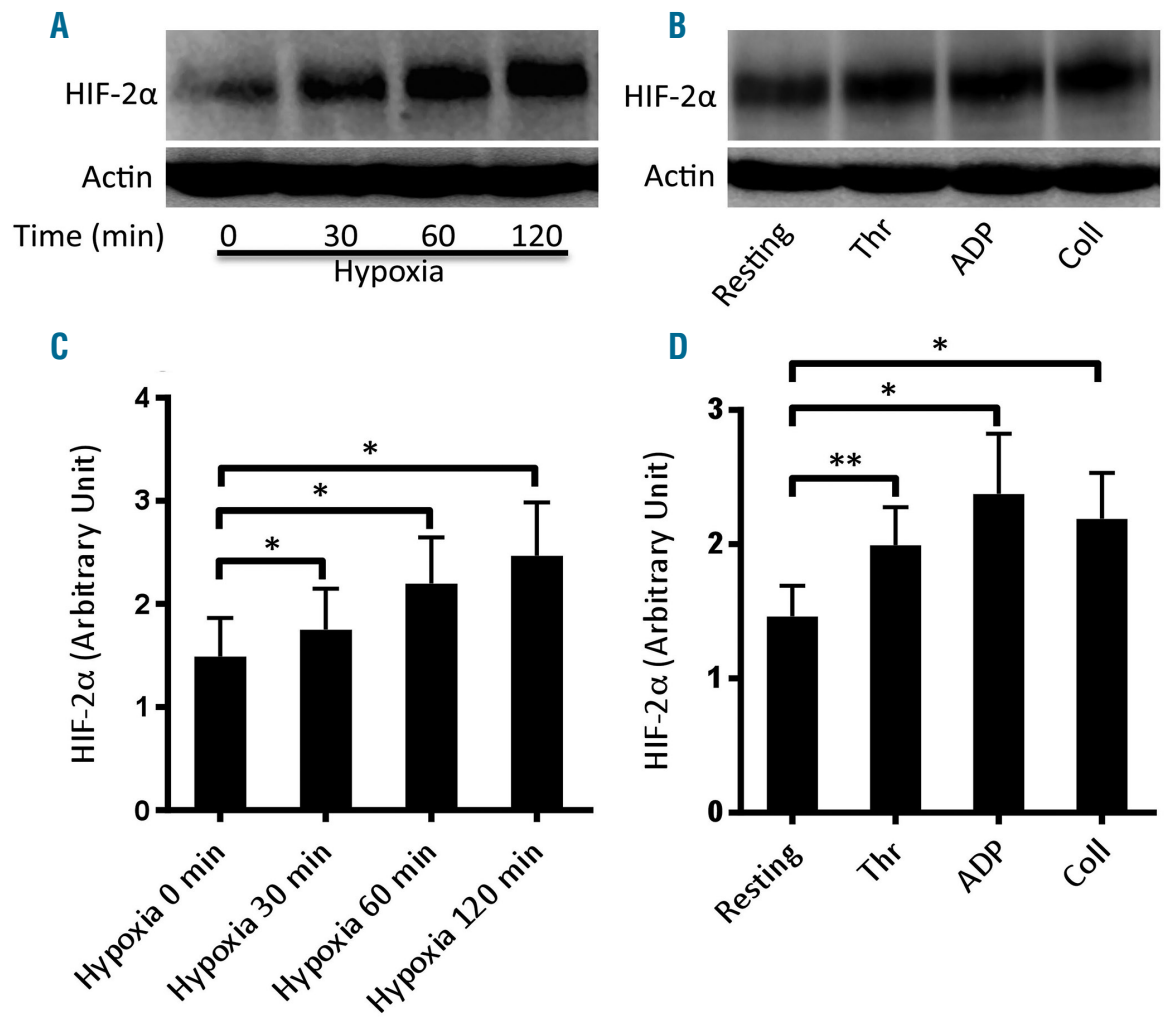

$\mathbf{E}$
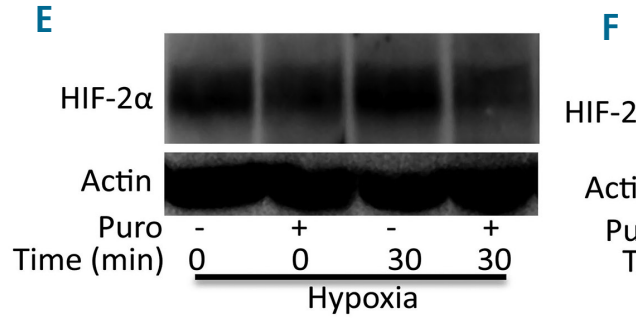

HIF-2 $\alpha$

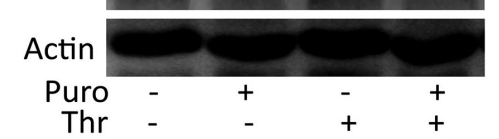

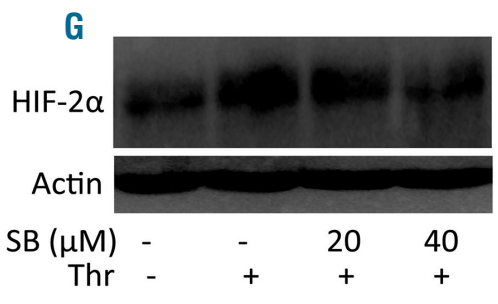

H
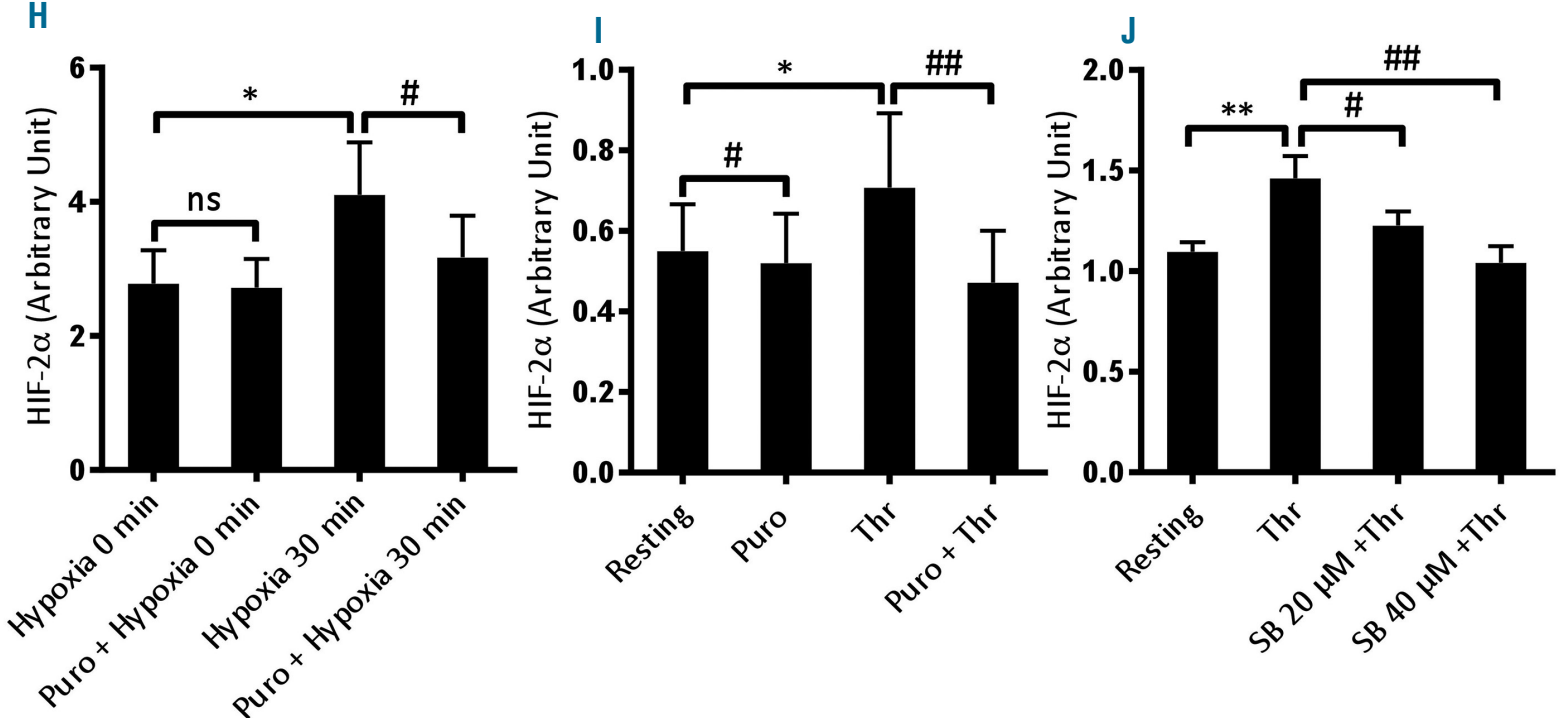

Figure 1. Enhanced expression of HIF-2 $\alpha$ in human platelets under hypoxia and upon stimulation with physiological agonists. (A, B) Western blot analysis showing expression of HIF- $2 \alpha$ in platelets exposed to either hypoxia $\left(1 \% \mathrm{O}_{2}, 5 \% \mathrm{CO}_{2}\right.$, and $\left.94 \% \mathrm{~N}_{2}\right)$ for the indicated times (A) or agonists (thrombin, Thr, $1 \mathrm{U} / \mathrm{mL}$; ADP, $10 \mu \mathrm{M}$; collagen, Coll, $10 \mu \mathrm{g} / \mathrm{mL}$ ) under non-stirring condition for $10 \mathrm{~min}$ at $37^{\circ} \mathrm{C}$ (B). (C, D) Corresponding densitometric analyses of HIF-2 $\alpha$ normalized to $\beta$-actin ( $\geq 3$ ). (E, F) Expression of HIF-2 $\alpha$ in platelets pretreated or not with puromycin (Puro, $10 \mathrm{mM}$ ) and then exposed to hypoxia (E) or thrombin (F). (H, I) Corresponding densitometric analyses of HIF-2 $\alpha$ normalized to $\beta$-actin ( $(n \geq 4)$. (G) HIF-2 $\alpha$ expression of platelets pretreated with SB202190 (SB, $20 \mu M$ and $40 \mu M)$. (J) Corresponding densitometric analysis of HIF-2 $\alpha$ normalized to $\beta$-actin $(n=6)$. Data are represented as the mean \pm standard error of mean of at least three different experiments. $* P<0.05 ; * * P<0.01 ; \# P<0.05 ; \# \# P<0.01$, analyzed by the Student $t$ test. 
ly, concurrent with the synthesis of HIF-2 $\alpha$. Puromycin $(10 \mathrm{mM})$ significantly attenuated PAI-1 expression in hypoxic cells (Figure 3A, D) as well as in hypoxia-mimetic-treated cells (Figure 3B, E). A prothrombotic phenotype associated with hypoxia may, therefore, be at least in part attributable to synthesis of PAI-1 by platelets under hypoxic stress.

PEV are membrane-bound cellular fragments ranging in size from 0.1 to $1 \mu \mathrm{m}$ that are shed by stimulated or stressed platelets. ${ }^{31,32} \mathrm{PEVs}$ are endowed with pro-coagulant properties and play a vital role in hemostatic responses. ${ }^{33,34}$ Exposure of platelets to hypoxia for $2 \mathrm{~h}$ led to extensive shedding of PEV, in numbers 1.5- to 3.0-fold higher than those released from normoxic counterparts under similar conditions (Figure 3C). Thus, it can be surmised that shedding of PEV together with production of PAI-1 by platelets would contribute significantly to a thrombogenic state in a hypoxic environment. In order to implicate hypoxia-induced platelet signaling in the pathogenesis of arterial thrombosis in vivo, we studied the effect of hypoxia-mimetics in a murine model of ferric chloride-induced mesenteric arteriolar thrombosis. Remarkably, as shown in Figure 3F, mice pretreated with DMOG $(400 \mathrm{mg} / \mathrm{kg})$ (Online Supplementary Video 1) or DFO (200 mg/kg) (Online
Supplementary Video 2) were found to exhibit significantly accelerated thrombus formation compared to that of control mice (Online Supplementary Video 3) (mean time to form first thrombus: DMOG, $7.16 \pm 0.66 \mathrm{~min}$; DFO, $7.0 \pm$ 0.86 ; control, $9.6 \pm 0.16 \mathrm{~min})$. Administration of hypoxiamimetics also evoked an increase in thrombus growth rate in mice (Figure $3 \mathrm{H}$ ) although the mean times to occlusion were not significantly different (Online Supplementary Figure S2). These results strongly suggest that platelet hypoxia signaling induces a prothrombotic state in vivo.

Hypoxia-mimetics induce shedding of extracellular vesicles and a rise in intracellular free calcium in human platelets

As hypoxic stress led to the release of EV from human platelets (Figure 3C), we examined the effect of the hypoxia-mimetics DMOG and DFO, which stabilize HIF$\alpha$ subunits by inhibition of prolyl hydroxylases, on platelets. Exposure of platelets to either DMOG $(1 \mathrm{mM})$ or $\mathrm{DFO}(1 \mathrm{mM})$ for $15 \mathrm{~min}$ at $37^{\circ} \mathrm{C}$ in a normoxic environment led to significantly higher expression of HIF-2 $\alpha$ (by $37 \%$ and $57.7 \%$, respectively) compared to that of the control platelets (Figure 4A, B). Remarkably, both hypoxia-mimetics induced significant shedding of $\mathrm{EV}$ from
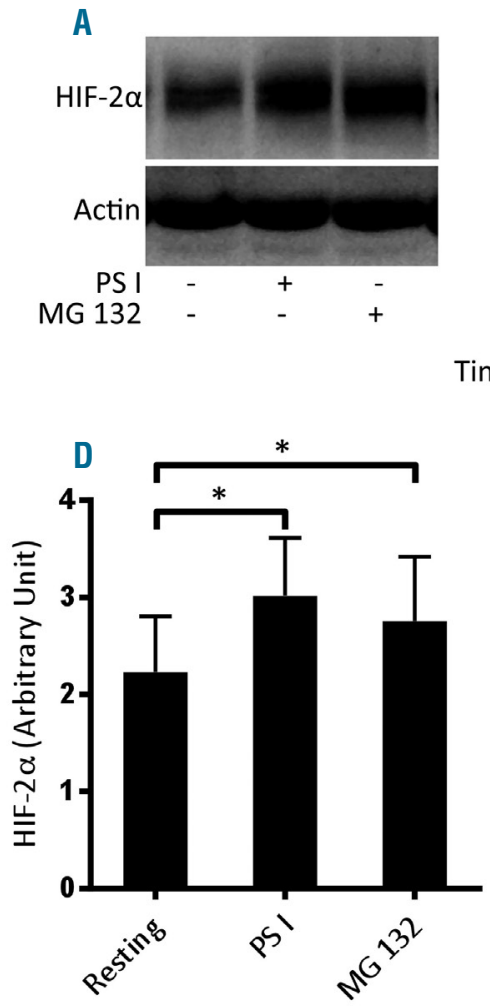
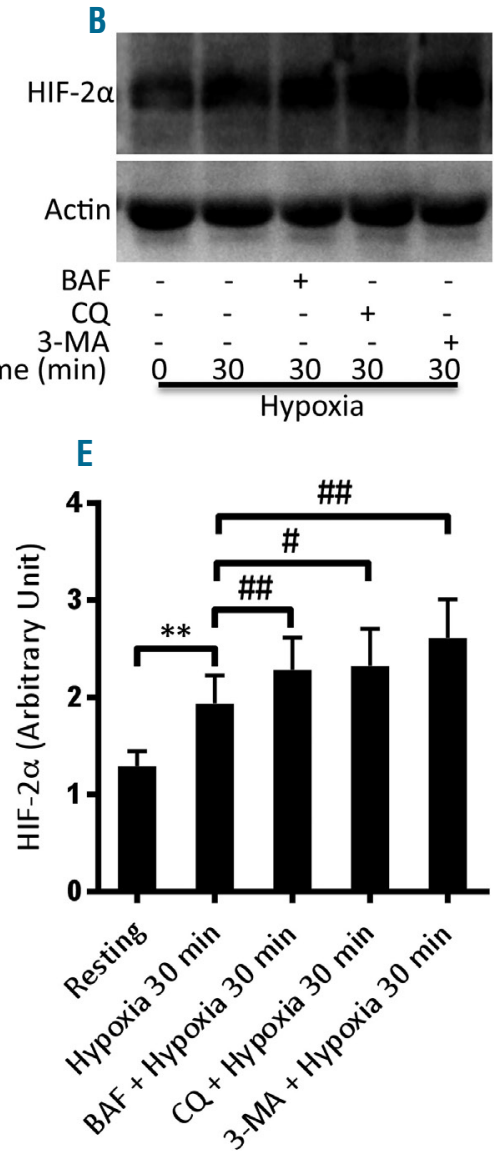
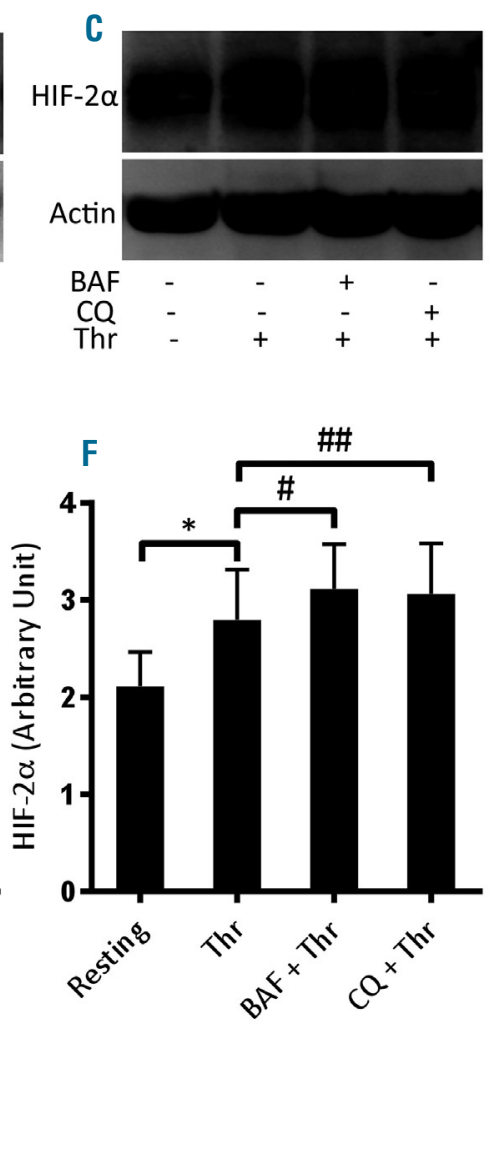

Figure 2. HIF-2 $\alpha$ degradation in human platelets. (A) Western blot analysis of HIF- $2 \alpha$ in platelets treated with either PSI (50 $\mu \mathrm{M})$ or MG132 ( $50 \mu \mathrm{M})$ for 30 min at room temperature. (D) Corresponding densitometric analysis of HIF- $2 \alpha$ normalized to $\beta$-actin ( $n=4)$. (B, C) Western blots of HIF-2 $\alpha$ in platelets pretreated with bafilomycin A1 (BAF, $250 \mathrm{nM}$ ), chloroquine (CQ, $50 \mu \mathrm{M}$ ) or 3-methyladenine (3-MA, $5 \mathrm{mM}$ ) for 30 min at room temperature as indicated. Cells were exposed to either hypoxia $\left(1 \% \mathrm{O}_{2}, 5 \% \mathrm{CO}_{2}\right.$, and $\left.94 \% \mathrm{~N}_{2}\right)$ for $30 \mathrm{~min}(\mathrm{~B})$, or thrombin (Thr, $\left.1 \mathrm{U} / \mathrm{mL}\right)$ for $10 \mathrm{~min}$ under non-stirring condition at $37^{\circ} \mathrm{C}(\mathrm{C})$. ( $\left.\mathrm{E}, \mathrm{F}\right) \mathrm{Corresponding} \mathrm{densitometric}$ analyses of HIF- $2 \alpha$ normalized to $\beta$-actin $(n=5)$. Data are represented as the mean \pm standard error of mean of at least three different experiments. * $P<0.05$; $* \star P<0.01 ; \# P<0.05 ; \# \# P<0.01$, analyzed by the Student $t$ test. 
platelets incubated for $2 \mathrm{~h}$ under normoxic conditions, which was comparable to the shedding from cells exposed to hypoxia for a similar duration (Figure $3 \mathrm{C}$ ). The release of EV from platelets evoked by shorter exposure (15 min) to DMOG (1 $\mathrm{mM})$ or DFO (1 $\mathrm{mM})$ was almost similar to that evoked by the longer incubation period (Figure 4C).

A rise in intracellular $\mathrm{Ca}^{2+},\left[\mathrm{Ca}^{2+}\right]_{\mathrm{i}}$, is a hallmark of platelet activation ${ }^{34}$ and plays a critical role in the release of $\mathrm{EV}^{35}$ We next examined the effect of hypoxia-mimetics on calcium homeostasis in human platelets. Incubation of
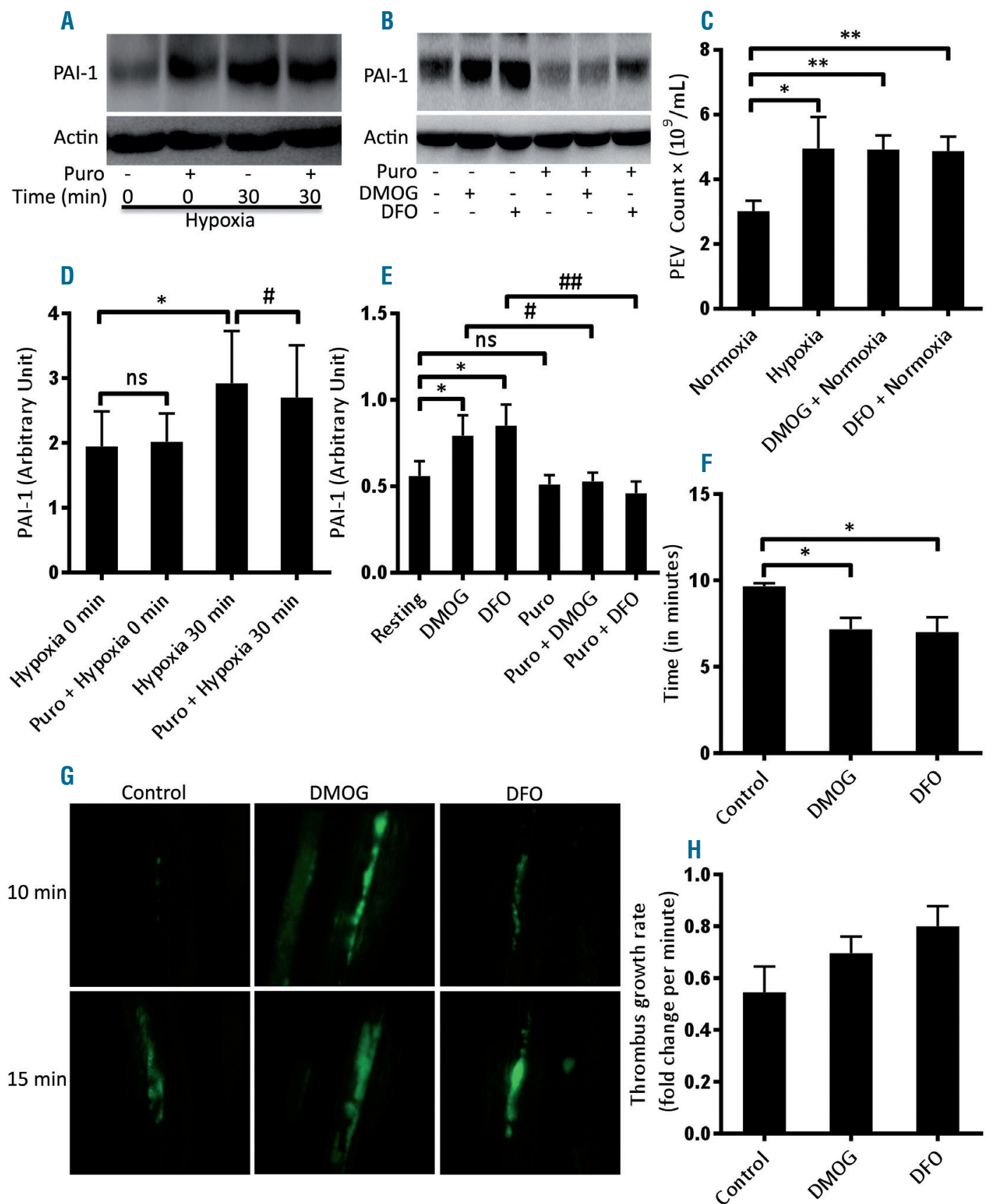

Figure 3. Hypoxia and hypoxia-mimetics induced translation of PAl-1 and shedding of extracellular vesicles from platelets. Hypoxia-mimetics promoted thrombogenesis in mice. (A, B) Western blots showing the expression of PAl-1 in platelets pretreated or not with puromycin (Puro, $10 \mathrm{mM}$ ) and then exposed to either hypoxia $\left(1 \% \mathrm{O}_{2}, 5 \% \mathrm{CO}_{2}\right.$, and $\left.94 \% \mathrm{~N}_{2}\right)$ for 30 min (A) or the hypoxia-mimetics dimethyloxalylglycine (DMOG, $1 \mathrm{mM}$ ) or deferoxamine (DFO, 1 mM) under normoxia for 30 min (B). (D, E) Corresponding densitometric analyses of PAl-1 expression normalized to $\beta$-actin $(n \geq 4)$. (C) Platelets were either exposed to hypoxia (1\% $\mathrm{O}_{2}, 5 \% \mathrm{CO}_{2}$, and $94 \% \mathrm{~N}_{2}$ ) for $2 \mathrm{~h}$ or pretreated with hypoxia-mimetics (DMOG, $1 \mathrm{mM}$; or DFO, $1 \mathrm{mM}$ ) under normoxia for $15 \mathrm{~min}$ at $37^{\circ} \mathrm{C}$ followed by $2 \mathrm{~h}$ at room temperature. Plateletderived extracellular vesicles (PEV) were isolated and analyzed with a Nanoparticle Tracking Analyzer $(n=6)$. (F-H) Thrombogenesis in mice treated with hypoxia-mimetics. $(\mathrm{F}, \mathrm{H})$ Bar diagrams representing time to first thrombus formation $(\mathrm{F})$ and thrombus growth rate $(\mathrm{H})$ in mice pre-administered vehicle (control), DMOG $(400 \mathrm{mg} / \mathrm{kg})$ or DFO (200 mg/kg). (G) Representative time-lapse images of mesenteric arteriolar thrombosis in mice pre-administered vehicle (control), DMOG, or DFO; the images were captured 10 or 15 min after ferric chloride injury of the mesenteric vessels $(n=3)$. Data are represented as the mean \pm standard error of mean of at least three

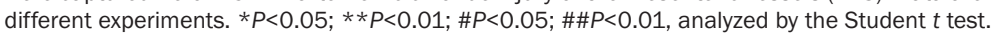


Fura-2 AM-stained platelets with either DMOG (1 mM) or $\mathrm{DFO}(1 \mathrm{mM})$ for $15 \mathrm{~min}$ at $37^{\circ} \mathrm{C}$ evoked significant rises in $\left[\mathrm{Ca}^{2+}\right]_{\mathrm{i}}$ (by 2.21- and 1.64-fold, respectively) (Figure 4D, E). To understand whether the entry of calcium from the external medium contributed to the DMOG/DFO-mediated rise in $\left[\mathrm{Ca}^{2+}\right]_{i}$, we pretreated cells with ethylene glycolbis( $\beta$-aminoethyl ether)-N,N,N',N'-tetraacetic acid
(EGTA, $1 \mathrm{mM}$ ) followed by incubation with either reagent. EGTA pretreatment led to significant reductions (by 69.7 and $77.66 \%$, respectively) in the rise of intracellular calcium induced by DMOG and DFO, suggesting that $\mathrm{Ca}^{2+}$ crosses the cell membrane and enters into the platelet cytoplasm in the presence of hypoxia-mimetics (Figure 4D, E). The influx of extracellular $\mathrm{Ca}^{2+}$ was further con-
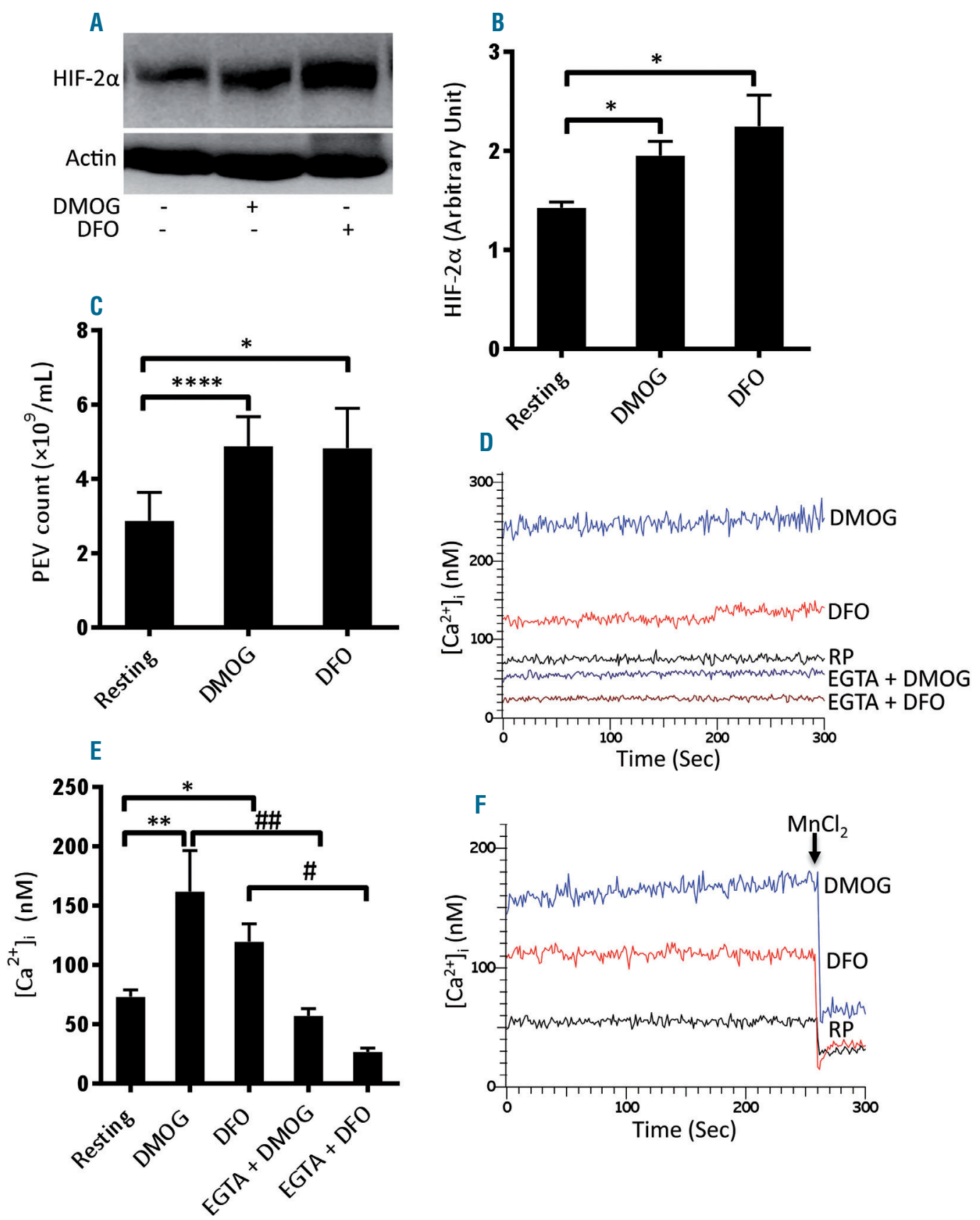

Figure 4. Hypoxia-mimetics induced increases in HIF-2 $\alpha$ expression, shedding of extracellular vesicles and a rise in intracellular Ca ${ }^{2+}$ in human platelets. (A) Western blot showing the expression of HIF- $2 \alpha$ in platelets treated with either dimethyloxalylglycine (DMOG, $1 \mathrm{mM}$ ) or deferoxamine (DFO, $1 \mathrm{mM}$ ) for $15 \mathrm{~min}$ at $37^{\circ} \mathrm{C}$ under normoxia. (B) Corresponding densitometric analysis of HIF-2 $\alpha$ normalized to $\beta$-actin $(n=4)$. (C) Platelets were exposed to DMOG (1 mM) or DFO (1 mM) for 15 min at $37^{\circ} \mathrm{C}$ in normoxic conditions. Platelet-derived extracellular vesicles (PEV) were isolated and analyzed with a Nanoparticle Tracking Analyzer ( $\mathrm{n}=3$ ). (D) Fura-2-loaded platelets were pretreated for 5 min with either calcium $(1 \mathrm{mM})$ or EGTA $(1 \mathrm{mM})$ and then incubated with DMOG $(1 \mathrm{mM})$ or DFO $(1 \mathrm{mM})$ for $15 \mathrm{~min}$ at $37^{\circ} \mathrm{C}$ under normoxic conditions. Intracellular $\mathrm{Ca}^{2+}$ was measured. RP, resting platelets. (E) Corresponding bar chart showing the intracellular calcium levels ( $\left.n=4\right)$. ( $F$ ) Fura-2-loaded platelets were pretreated with DMOG or DFO before the addition of $\mathrm{MnCl}_{2}(2 \mathrm{mM})$ after $260 \mathrm{sec}$ and fluorescence was recorded ( $\left.n=3\right)$. Data are represented as the

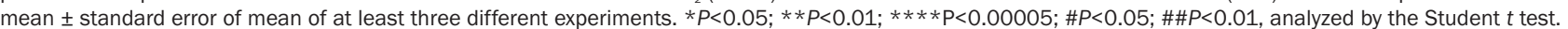


firmed by incubating platelets with $\mathrm{Mn}^{2+}$, which crosses the surface membrane similarly to $\mathrm{Ca}^{2+}$ and quenches Fura-2 fluorescence. ${ }^{23}$ When $\mathrm{MnCl}_{2}(2 \mathrm{mM})$ was added to Fura-2-labeled platelets pretreated with hypoxia-mimetics, there was an abrupt decrease in fluorescence (by $54.15 \%$ and $68.56 \%$ in DMOG- and DFO-treated cells, respectively) (Figure 4F), validating the entry of divalent cations into platelets stimulated with hypoxia-mimetics. The rise in intracellular calcium and release of EV induced in the presence of hypoxia-mimetics underscored a significant shift of platelet biology to a prothrombotic phenotype.

\section{Platelets from patients with chronic obstructive pul- monary disease have higher expression of HIF- $2 \alpha$ and PAI-1 than those from healthy counterparts}

COPD is a serious global public health problem characterized by progressive, persistent airflow limitation. ${ }^{36}$ Patients with COPD are reported to have 'hyperactive' platelets in the circulation and an increased risk of atherothrombotic events. ${ }^{12,14,15,37}$ As expression of HIF-2 $\alpha$ and PAI-1 was significantly higher in platelets exposed to hypoxic stress, we investigated whether platelets from patients with COPD, who are exposed to low arterial $\mathrm{PaO}_{2}$, have greater expression of these proteins. We performed western blot analysis on platelets isolated from ten patients with $\mathrm{COPD}\left(\mathrm{PaO}_{2}<60 \mathrm{mmHg}\right)$ and an equal number of age-matched healthy controls $\left(\mathrm{PaO}_{2}>90\right.$ $\mathrm{mmHg}$. Platelets from patients with COPD were found to have significantly higher expression of HIF-2 $\alpha$ as well as PAI-1 (by $82.50 \%$ and $80 \%$, respectively) when compared to platelets from healthy controls (Figure 5A-D).

\section{Platelets from high altitude residents have higher expression of HIF-2 $\alpha$ and PAI-1 than those from lowlander counterparts}

As people in oxygen-compromised environments such as those living at a high altitude are reported to have a higher incidence of thrombosis, ${ }^{11}$ we next studied the expression of HIF- $2 \alpha$ and PAI- 1 in platelets from individuals living $2200 \mathrm{~m}$ above sea level. Coherently with data from patients with COPD, high altitude residents, too, were found to have significantly higher expression of platelet-specific HIF-2 $\alpha$ and PAI-1 (increased by $164.28 \%$ and $164.26 \%$, respectively) compared to their lowlander counterparts (Figure 5E-H).

\section{Discussion}

Of the three isoforms of the catalytic subunit of hypoxia-inducible factor, HIF-1 $\alpha$ is known to be ubiquitously expressed while the presence of the HIF- $2 \alpha$ and HIF- $3 \alpha$ is cell-specific. ${ }^{4,5}$ For example, HIF- $2 \alpha$ is expressed in human embryonic kidney 293 cells $^{26}$ and neutrophils ${ }^{27}$ while HIF$3 \alpha$ has been reported to be expressed in lung epithelial cells. ${ }^{5}$ In this study, we demonstrated, for the first time, that there is significant expression of HIF-2 $\alpha$ in human platelets (Figure 1). Enucleate platelets are known to carry functional mRNA transcripts of specific genes with limited protein synthesizing ability. ${ }^{38}$ We found significant expression of both HIF- $1 \alpha$ and $-2 \alpha$ mRNA in platelets (Online Supplementary Figure S1) although HIF-1 $\alpha$, unlike HIF-2 $\alpha$, was hardly detectable on western blot analysis (data not shown).
The $\alpha$ subunit of HIF is stabilized under low oxygen conditions, ${ }^{2}$ as well as upon exposure of cells to nonhypoxic stimuli such as thrombin. ${ }^{7}$ During the process of hemostasis platelets are stimulated by agonists leading to the formation of tightly packed aggregates, which restrict access of molecular oxygen to individual cells. We, therefore, examined hypoxic adaptation of platelets and their reaction to hemostatic stimuli. HIF-2 $\alpha$ was found to increase significantly and progressively with time when platelets were exposed to a low oxygen environment (1\% $\mathrm{O}_{2}, 5 \% \mathrm{CO}_{2}$ and $94 \% \mathrm{~N}_{2}$ ) (Figure 1A, C). Strikingly, physiological agonists, such as thrombin, ADP and collagen, profoundly enhanced HIF- $2 \alpha$ expression in platelets in a normoxic environment (Figure 1B, D), which reflects the presence of oxygen-independent regulation of $\mathrm{HIF}-2 \alpha$, too, in these cells.

As the turnover of HIF protein is known to be high, we studied its dynamic regulation in enucleate platelets, which have restricted protein-synthesizing ability. Pretreatment of platelets with puromycin partially prevented the rise in HIF-2 $\alpha$ elicited in the presence of hypoxia or platelet agonists (Figure 1E, F, H, I), which was consistent with active synthesis of HIF- $2 \alpha$ in platelets. p38 MAPK has earlier been implicated in upregulation of HIF$1 \alpha$ in vascular smooth muscle cells. ${ }^{7}$ As human platelets are known to express p38 $\mathrm{MAPK},{ }^{28}$ we determined its role in regulating the synthesis of HIF- $2 \alpha$ in thrombin-activated platelets. Pretreatment of platelets with $20 \mu \mathrm{M}$ and 40 $\mu \mathrm{M}$ SB202190 (an inhibitor of p38 MAPK) led to significant decreases in the levels of HIF-2 $\alpha$ (by $16.43 \%$ and $28.77 \%$, respectively) (Figure $1 \mathrm{G}, \mathrm{J}$ ), thus implicating p38 MAPK in HIF- $2 \alpha$ generation in platelets. It cannot be ruled out that other factors are involved in the regulation of HIF$2 \alpha$ synthesis in platelets.

The proteasome is known to degrade HIF in a pVHLdependent manner upon hydroxylation of its proline residues by prolyl hydroxylases in the presence of oxygen. Lysosomes, too, have recently been implicated in cleavage of HIF either by macroautophagy ${ }^{9}$ or by chaperone-mediated autophagy. ${ }^{10}$ It has been demonstrated that platelets possess a functionally active proteasome system. ${ }^{29}$ In order to understand the role of proteasome peptidase activity in determining HIF stability in platelets, we examined changes in HIF-2 $\alpha$ expression in the presence of proteasome inhibitors, PSI and MG 132. Attenuation of proteasome activity was associated with significant rises in the levels of HIF- $2 \alpha$ in platelets (Figure $2 \mathrm{~A}, \mathrm{D})$, suggestive of constitutive proteasomal degradation of HIF-2 $\alpha$. Next, we examined the role of lysosomes and macroautophagy in HIF- $2 \alpha$ proteolysis by pretreating cells with bafilomycin A1 (which blocks the activity of vacuolar-ATPase proton pumps), chloroquine (which neutralizes the acidic environment within the lysosome compartment) or 3-methyladenine (a selective inhibitor of macroautophagy). Inhibition of lysosomal activity as well as macroautophagy resulted in significant enhancement of HIF-2 $\alpha$ levels in platelets (Figure 2B, C, E, F). Taken together, these results imply that the proteolysis of HIF- $2 \alpha$ by proteasomes and lysosomes is involved in the regulation of the steady-state level of the factor in platelets.

PAI-1 is a serine protease responsible for the stabilization of thrombi. Platelets are known to synthesize functionally active PAI-1 from pre-existing mRNA. ${ }^{21}$ PAI-1, too, is a target gene for HIF- $2 \alpha$ in renal carcinoma cells ${ }^{30} \mathrm{We}$ 
found upregulation of HIF-2 $\alpha$ expression in platelets under hypoxic stress or upon exposure to hypoxia-mimetics, which stabilize HIF- $2 \alpha$ by inhibiting prolyl hydroxylases. In parallel, we documented significantly higher PAI1 expression in platelets (Figure $3 \mathrm{~A}, \mathrm{~B}, \mathrm{D}, \mathrm{E}$ ), thus underscoring the possibility of HIF- $2 \alpha$-mediated regulation of PAI-1 synthesis. EV shed by stimulated or stressed platelets $^{31,32}$ are endowed with pro-coagulant properties, and play an important role in hemostatic responses. ${ }^{33,34}$ Remarkably, the release of PEV from platelets exposed to hypoxia was enhanced by 1.5 - to 3 -fold compared to that from platelets in a normoxic environment (Figure 3C). Both synthesis of PAI-1 and release of EV by platelets contribute to a prevailing prothrombotic state in an organism in a hypoxic environment.

We next examined the effect of the hypoxia-mimetics DMOG and DFO on platelets in a normoxic environment. Each of these drugs induced significantly higher expression of HIF-2 $\alpha$ (Figure 4A, B) and triggered extensive shedding of EV from platelets (Figure 4C), which was compa-
A
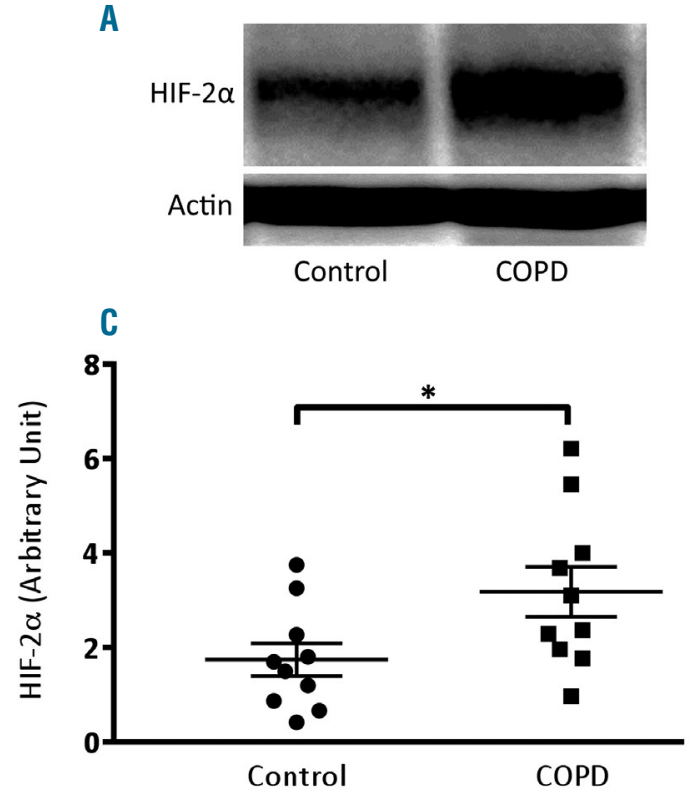

$\mathbf{E}$

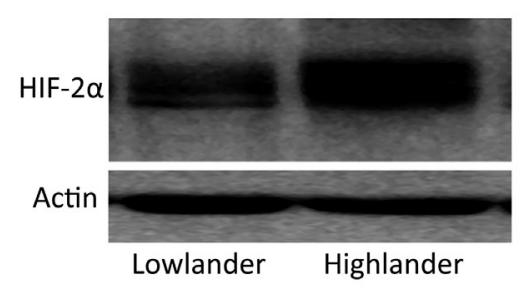

G

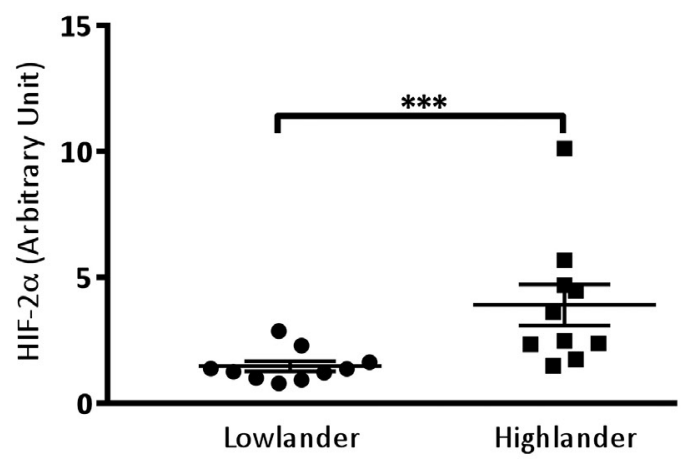

B

PAI-1

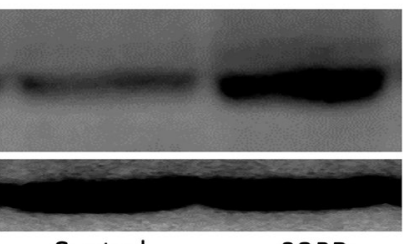

Control

COPD

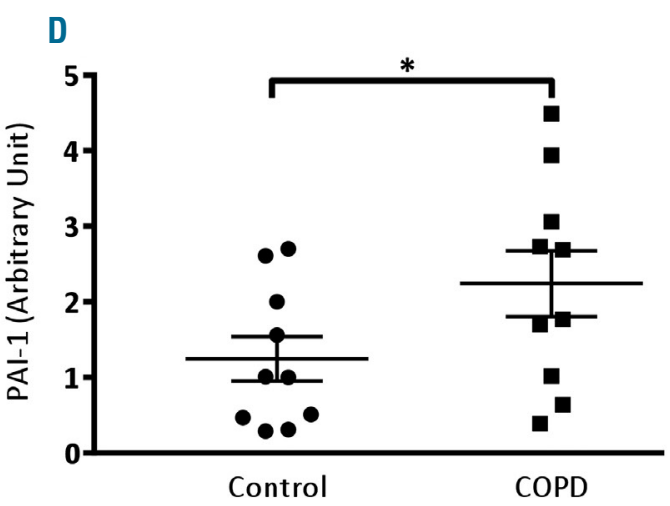

$\mathbf{F}$

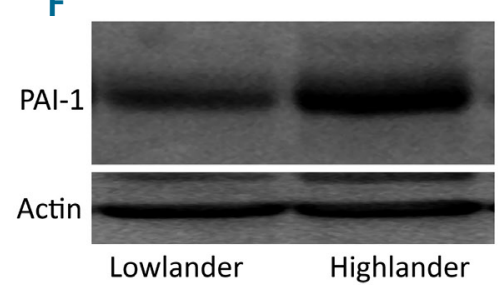

H

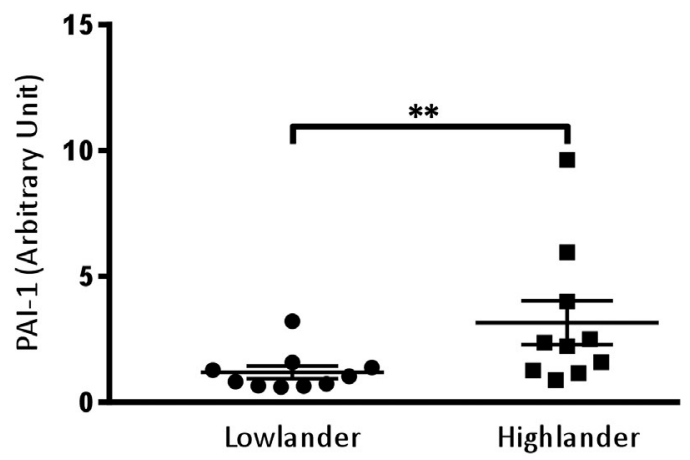

Figure 5. Platelets from patients with chronic obstructive pulmonary disease and from high altitude residents have higher expression of HIF-2 $\alpha$ and PAI-1. (A, B, E, F) Immunoblotting against HIF-2 $\alpha$ (A, E) and PAI-1 (B, F) in platelets obtained from patients with chronic obstructive pulmonary disease (COPD) ( $n=10)(A, B)$ and highaltitude residents $(n=10)(E, F)$ along with respective controls $(n=10)$. (C, D, G, H) Corresponding densitometric analyses normalized to $\beta$-actin. Data are represented as the mean \pm standard error of mean of ten different experiments. ${ }^{*} P<0.05 ; * \star P<0.01$, analyzed by the Mann Whitney test. 
rable to that from platelets exposed to hypoxia (Figure 3C). Hypoxia-mimetics also induced accelerated arterial thrombosis in mice (Figure 3F-H). As intracellular calcium plays a critical role in platelet activation, ${ }^{34}$ we determined the effect of hypoxia-mimetics on $\mathrm{Ca}^{2+}$ flux in human platelets. Both DMOG and DFO elicited significant rises in cytosolic $\mathrm{Ca}^{2+}$ (by 2.21- and 1.64-fold, respectively) when calcium was included in the suspension buffer (Figure 4D, E). Interestingly, chelation of external calcium with EGTA led to a substantial drop in the DMOG- or DFO-induced rise in platelet cytosolic calcium (by $64.70 \%$ and $77.66 \%$, respectively) (Figure 4D, E), a finding consistent with $\mathrm{Ca}^{2+}$ entry from the external medium in the presence of hypoxia-mimetics. $\mathrm{Ca}^{2+}$ influx was further validated by incubating platelets with $\mathrm{Mn}^{2+}$, which led to quenching of Fura-2 fluorescence in DMOG- and DFOtreated platelets (Figure 4F). Both the rise in intracellular calcium and the release of EV evoked by hypoxia-mimetics underscored a significant shift to a prothrombotic phenotype of platelets marked with higher expression and stabilization of HIF-2 $\alpha$.

Patients with COPD have 'hyperactive' platelets in their circulation, which contribute to the prothrombotic attributes of this disease $\mathrm{e}^{12,37}$ and cardiovascular mortality. ${ }^{14,39}$ Recently, neutrophils from patients with COPD were demonstrated to have elevated expression of HIF- $2 \alpha .{ }^{27} \mathrm{We}$ investigated whether exposure to low arterial $\mathrm{PaO}_{2}(<60$ $\mathrm{mmHg}$ ) in COPD would induce changes in circulating platelets similar to those seen in isolated cells subjected to hypoxic stress in vitro. Remarkably, platelets from patients with COPD were found to have significantly higher expression of HIF- $2 \alpha$ and PAI-1 as compared to the platelets from their healthy counterparts (Figure 5A-D), which provides a molecular underpinning for the thrombogenic phenotype associated with COPD.

Oxygen-compromised environments such as high altitude are also associated with increased platelet activation, ${ }^{11}$ attributable to upregulation of the cysteine protease, calpain. ${ }^{16}$ We wondered whether a highland population (liv- ing $2200 \mathrm{~m}$ above sea level) would have a platelet phenotype similar to that of platelets isolated from patients with COPD. Notably, these high altitude residents, too, were found to have significantly higher expression of HIF-2 $\alpha$ and PAI- 1 in platelets as compared to their lowlander counterparts (Figure 5E-H). This is the first report on hypoxic changes in circulating platelets from either patients with COPD or from people living at a high altitude.

In conclusion, our study elucidates adaptive signaling in platelets in response to the challenges of a hypoxic environment and agonist stimulation, which closely correlate with the microenvironment within a thrombus. Under either of these situations platelets synthesize HIF-2 $\alpha$ and the thrombogenic polypeptide PAI-1, and also release abundant numbers of EV. Concordantly, circulating platelets from patients with COPD, which is a condition predisposing to atherothrombotic events, as well as high altitude residents also exhibited significantly higher expression of HIF- $2 \alpha$ and PAI-1. We further established that the steady-state level of HIF- $2 \alpha$, which is a shortlived polypeptide with a high turnover rate, is determined in platelets by synthesis in a MAPK-dependent manner and by proteolytic degradation through the proteasomal and lysosomal systems. Since hypoxic adaptation in platelets contributes to the prothrombotic state, targeting platelet hypoxia signaling could be an effective, new-generation anti-thrombotic strategy.

\section{Acknowledgments}

This research was supported by a J. C. Bose National Fellowship and grants received by D. Dash from the Department of Biotechnology (DBT) (BT/PR20645/BRB/10/1541/2016), Science and Engineering Research Board (SERB), Department of Science and Technology (DST), Government of India, the Indian Council of Medical Research (ICMR) and the Council of Scientific and Industrial Research (CSIR). SNC is a recipient of a Senior Research Fellowship from the Indian Council of Medical Research (ICMR). We thank M/S Bio-Rad for extending the facility for droplet digital PCR.

\section{References}

1. Hayashi T, Mogami H, Murakami Y, et al. Real-time analysis of platelet aggregation and procoagulant activity during thrombus formation in vivo. Pflugers Archiv. 2008;456(6):1239-1251

2. Schofield CJ, Ratcliffe PJ. Oxygen sensing by HIF hydroxylases. Nat Revi Mol Cell Biol. 2004;5(5):343-354

3. Karuppagounder SS, Ratan RR. Hypoxiainducible factor prolyl hydroxylase inhibition: robust new target or another big bust for stroke therapeutics? J Cereb Blood Flow Metab. 2012;32(7):1347-1361.

4. Maxwell PH, Wiesener MS, Chang GW, et al. The tumour suppressor protein VHL targets hypoxia-inducible factors for oxygendependent proteolysis. Nature. 1999;399 (6733):271-275

5. Li OF, Wang XR, Yang YW, Lin H. Hypoxia upregulates hypoxia inducible factor (HIF)3alpha expression in lung epithelial cells: characterization and comparison with HIF1alpha. Cell Res. 2006;16(6):548-558.
6. Bruick RK, McKnight SL. A conserved family of prolyl-4-hydroxylases that modify HIF Science. 2001;294(5545):1337-1340.

7. Gorlach A, Diebold I, Schini-Kerth VB, et al. Thrombin activates the hypoxia-inducible factor-1 signaling pathway in vascular smooth muscle cells: role of the p22(phox)containing NADPH oxidase. Circ Res. 2001;89(1):47-54

8. Mori H, Yao Y, Learman BS, et al. Induction of WNT11 by hypoxia and hypoxiainducible factor- $1 \alpha$ regulates cell proliferation, migration and invasion. Sci Rep. 2016;6:21520

9. Liu XD, Yao J, Tripathi DN, et al. Autophagy mediates HIF2alpha degradation and suppresses renal tumorigenesis. Oncogene. 2015;34(19):2450-2460.

10. Hubbi ME, Hu H, Kshitiz, Ahmed I, Levchenko A, Semenza GL. Chaperonemediated autophagy targets hypoxiainducible factor-1alpha (HIF-1alpha) for lysosomal degradation. J Biol Chem. 2013;288(15):10703-10714.

11. Gupta N, Ashraf MZ. Exposure to high alti- tude: a risk factor for venous thromboembolism? Semin Thromb Hemost. 2012;38(2): 156-163.

12. Wedzicha JA, Syndercombe-Court D, Tan KC. Increased platelet aggregate formation in patients with chronic airflow obstruction and hypoxaemia. Thorax. 1991;46(7):504507.

13. Oga $\mathrm{T}$, Chin $\mathrm{K}$, Tabuchi A, et al. Effects of obstructive sleep apnea with intermittent hypoxia on platelet aggregability. J Atheroscler Thromb. 2009;16(6):862-869.

14. Curkendall SM, DeLuise C, Jones JK, et al. Cardiovascular disease in patients with chronic obstructive pulmonary disease, Saskatchewan Canada cardiovascular disease in COPD patients. Ann Epidemiol. 2006;16(1):63-70.

15. Fimognari FL, Scarlata S, Conte ME, Incalzi RA. Mechanisms of atherothrombosis in chronic obstructive pulmonary disease. Int J Chron Obstruct Pulmon Dis. 2008;3(1):8996.

16. Tyagi T, Ahmad S, Gupta N, et al. Altered expression of platelet proteins and calpain 
activity mediate hypoxia-induced prothrombotic phenotype. Blood. 2014;123(8): 1250-1260.

17. Yan S-F, Zou YS, Gao Y, et al. Tissue factor transcription driven by Egr-1 is a critical mechanism of murine pulmonary fibrin deposition in hypoxia. Proc Natl Acad Sci U S A. 1998;95(14):8298-8303.

18. Pinsky DJ, Liao H, Lawson CA, et al. Coordinated induction of plasminogen activator inhibitor-1 (PAI-1) and inhibition of plasminogen activator gene expression by hypoxia promotes pulmonary vascular fibrin deposition. J Clin Invest. 1998;102(5): 919-928.

19. Weyrich AS, Dixon DA, Pabla R, et al. Signal-dependent translation of a regulatory protein, Bcl-3, in activated human platelets. Proc Natl Acad Sci U S A. 1998;95(10):55565561.

20. Lindemann S, Tolley ND, Dixon DA, et al. Activated platelets mediate inflammatory signaling by regulated interleukin 1 beta synthesis. J Cell Biol. 2001;154(3):485-490.

21. Brogren H, Karlsson L, Andersson M, Wang L, Erlinge D, Jern S. Platelets synthesize large amounts of active plasminogen activator inhibitor 1. Blood. 2004;104(13):3943-3948.

22. Panes O, Matus V, Saez CG, Quiroga T, Pereira J, Mezzano D. Human platelets synthesize and express functional tissue factor. Blood. 2007;109(12):5242-5250

23. Kumari S, Dash D. Melatonin elevates intracellular free calcium in human platelets by inositol 1,4,5-trisphosphate independent mechanism. FEBS Lett. 2011;585(14):23452351.

24. Kulkarni PP, Tiwari A, Singh N, Gautam D, Sonkar VK, Agarwal V, Dash D. Aerobic gly- colysis fuels platelet activation: small-molecule modulators of platelet metabolism as anti-thrombotic agents. Haematologica 2019;104(4):806-818.

25. Grynkiewicz G, Poenie M, Tsien RY. A new generation of $\mathrm{Ca} 2+$ indicators with greatly improved fluorescence properties. J Biol Chem. 1985;260(6):3440-3450.

26. Selfridge AC, Cavadas MA, Scholz CC, et al. Hypercapnia suppresses the HIF-dependent adaptive response to hypoxia. J Biol Chem. 2016;291(22):11800-11808.

27. Thompson AA, Elks PM, Marriott HM, et al Hypoxia-inducible factor 2alpha regulates key neutrophil functions in humans, mice, and zebrafish. Blood. 2014;123(3):366-376.

28. Kramer RM, Roberts EF, Strifler BA Johnstone EM. Thrombin induces activation of p38 MAP kinase in human platelets. J Biol Chem. 1995;270(46):27395-27398.

29. Nayak MK, Kumar K, Dash D. Regulation of proteasome activity in activated human platelets. Cell Calcium. 2011;49(4):226-232.

30. Carroll VA, Ashcroft M. Role of hypoxiainducible factor (HIF)-1alpha versus HIF2alpha in the regulation of HIF target genes in response to hypoxia, insulin-like growth factor-I, or loss of von Hippel-Lindau function: implications for targeting the HIF pathway. Cancer Res. 2006;66(12):6264-6270.

31. Heijnen HF, Schiel AE, Fijnheer R, Geuze HJ, Sixma JJ. Activated platelets release two types of membrane vesicles: microvesicles by surface shedding and exosomes derived from exocytosis of multivesicular bodies and alpha-granules. Blood. 1999;94(11): 3791-3799.

32. Reininger AJ, Heijnen HFG, Schumann $H$, Specht HM, Schramm W, Ruggeri ZM.
Mechanism of platelet adhesion to von Willebrand factor and microparticle formation under high shear stress. Blood 2006;107(9):3537-3545.

33. Sinauridze EI, Kireev DA, Popenko NY, et al Platelet microparticle membranes have 50 to 100 -fold higher specific procoagulant activity than activated platelets. Thromb Haemost. 2007;97(3):425-434.

34. Mallick RL, Kumari S, Singh N, Sonkar VK, Dash D. Prion protein fragment (106-126) induces prothrombotic state by raising platelet intracellular calcium and microparticle release. Cell Calcium. 2015;57(4):300311.

35. Huber J, Vales A Mitulovic G et al. Oxidized membrane vesicles and blebs from apoptotic cells contain biologically active oxidized phospholipids that induce monocyte-endothelial interactions. Arterioscler Thromb Vasc Biol. 2002;22(1):101-107.

36. Wouters EF, Groenewegen KH, Dentener $\mathrm{MA}$, Vernooy JH. Systemic inflammation in chronic obstructive pulmonary disease: the role of exacerbations. Proc Am Thorac Soc. 2007;4(8):626-634

37. Maclay JD, McAllister DA, Johnston S, et al Increased platelet activation in patients with stable and acute exacerbation of COPD. Thorax. 2011;66(9):769-774.

38. McRedmond JP, Park SD, Reilly DF, et al Integration of proteomics and genomics in platelets: a profile of platelet proteins and platelet-specific genes. Mol Cell Proteomics. 2004;3(2):133-144

39. Hansell AL, Walk JA, Soriano JB. What do chronic obstructive pulmonary disease patients die from? A multiple cause coding analysis. Eur Respir J 2003; 22: 809-814. 